\title{
DIORAMA SENSORIAL INTERDISCIPLINAR: UMA VIAGEM COM A EXPEDIÇÃO BEAGLE, DE CHARLES DARWIN
}

\section{INTERDISCIPLINARY SENSORY DIORAMA: A VOYAGE WITH THE BEAGLE EXPEDITION OF CHARLES DARWIN}

DOI: http://dx.doi.org/10.5965/1984317816012020385

Fernanda Maria Trentini Carneiro

Instituto Federal de Santa Catarina

fernanda.trentini@ifsc.edu.br

Alessandra Daniele da Silva Boos
Instituto Federal de Santa Catarina aleboos@gmail.com

Vanessa Arlésia de Souza Ferretti

Universidade Estadual de Mato Grosso do Sul

vanessa.arlesia@gmail.com

\begin{abstract}
RESUMO
O artigo apresenta um projeto interdisciplinar realizado com alunos dos primeiros anos dos cursos técnicos em química e informática do IFSC-Gaspar. A atividade objetivou a construção de dioramas sensoriais resultantes de uma pesquisa sobre a expedição Beagle, da qual participou Charles Darwin entre 1831 e 1836. Diorama é um tipo de maquete que apresenta de forma artística uma situação real, ou seja, uma representação tridimensional de uma cena. O diorama foi pensando como objeto sensorial de maneira a torná-lo acessível ao público geral e público de $\mathrm{PcD}$, especificamente, pessoas com deficiência visual. Este trabalho envolveu as unidades curriculares de Artes, Biologia e Português e contou com o apoio da unidade curricular de História e do grupo de trabalho de materiais adaptados da instituição. Ao todo foram realizados vinte e dois dioramas relacionados a vinte e duas localidades por onde Charles Darwin passou com a expedição. Os resultados apontam que o projeto interdisciplinar promove maior engajamento dos discentes com as práticas de pesquisa e de inclusão, bem como apropriação de conhecimentos de modo crítico e articulado às demandas sociais do tempo presente.
\end{abstract}

Palavras-chave: Educação Inclusiva. Materiais adaptados. Exposição tátil. Acessibilidade. Interdisciplinaridade.

\begin{abstract}
This paper presents an interdisciplinary project carried out with students of the first year of the technical courses in chemistry and informatics of the Federal Institute of Santa Catarina (IFSC) Gaspar. The activity aimed to create sensory dioramas resulting from a research on the HSM Beagle expedition, joined by Charles Darwin between 1831 and 1836. Diorama is a type of model that presents in an artistic way a real situation, that is to say, it is a tridimensional representation of a scene. The diorama was conceived as a sensory object so as to make it accessible to the general public as well as to people with disabilities, specifically, visually impaired people. This work involved three subjects: Arts, Biology and Portuguese but it was also supported by History and the working group of adapted materials of the institution. Twenty-two dioramas related to twenty-two locations visited by Charles Darwin with the Beagle Expedition were made. The results indicate that the interdisciplinary project promotes greater involvement of students in research and inclusion practices, as well as appropriation of knowledge in a critical and articulated way to the social demands of the
\end{abstract}


present time.

Keywords: Inclusive education. Adapted materials. Tactile exhibition. Accessibility. Interdisciplinarity.

\section{INTRODUÇÃO}

Nos últimos anos, tem havido no Brasil maiores esforços no sentido de promover a inclusão social de pessoas com deficiência (PcD). Um exemplo disso é a recente aprovação do Estatuto da pessoa com deficiência (Lei 13.146/2015), segundo o qual, é direito da $\mathrm{PcD}$, por exemplo, o acesso e a permanência no sistema educacional, e é dever das instituições a promoção de práticas pedagógicas inclusivas.

Convergentemente, o Instituto Federal de Santa Catarina (IFSC) tem assumido como sua missão "promover a inclusão e formar cidadãos, por meio da educação profissional, científica e tecnológica, gerando, difundindo e aplicando conhecimento e inovação, contribuindo para o desenvolvimento socioeconômico e cultural” (IFSC, PDI 2015-2019). Tal objetivo inclui também a promoção do acesso de PcD à instituição, uma vez que essas também são parte constitutiva do corpo social e, portanto, devem ser contempladas pelas políticas públicas de formação educacional de cidadãos e cidadãs.

Nesse cenário, felizmente o IFSC tem recebido esse público e tem trabalhado para que ele se envolva de fato nas dinâmicas educacionais da instituição. Tal processo passa pela necessidade não somente de superação de barreiras (arquitetônicas, atitudinais, tecnológicas etc.), conforme dispõe a legislação, mas também pela mobilização, em prol de práticas educacionais inclusivas, do corpo docente, da gestão, dos demais trabalhadores da instituição e, inclusive, dos próprios discentes de modo geral, que têm recebido PcD como suas colegas de classe.

É justamente desse cenário que emerge a proposta apresentada neste artigo. Em outras palavras, trata-se da apresentação e discussão de um projeto interdisciplinar, intitulado "Uma viagem com a Expedição Beagle", realizado com alunos dos primeiros anos dos cursos técnicos integrados em química e informática, do IFSC-Gaspar. O objetivo principal da atividade foi a construção de dioramas 
acessíveis a pessoas cegas.

O artigo, então, congrega discussões acerca da prática de projetos interdisciplinares como ferramenta para resolução questões sociais relevantes global e localmente, por um lado, e práticas educacionais acessíveis a PcD, especificamente a pessoas cegas, por outro lado. Atravessam a abordagem, ainda, aspectos relacionados à necessidade de articular conteúdos curriculares às práticas situadas de vivências reais e à apropriação e aplicação de conhecimentos no âmbito dessas vivências.

Para tratar de tais questões, a partir daqui o artigo i) discute a necessidade de práticas educacionais inclusivas; ii) apresenta a pertinência do trabalho via projetos interdisciplinares como forma de fomentar esse tipo de prática; iii) descreve o projeto "Uma viagem com a Expedição Beagle" e iv) discute essa atividade em relação às práticas de inclusão e de (re)construção de conhecimentos nas disciplinas de Artes, Biologia e Língua Portuguesa.

\section{PRÁTICAS EDUCACIONAIS E INCLUSÃO}

$\mathrm{Na}$ história das instituições escolares, a dicotomia entre normalidade e anormalidade fundamentou inúmeras práticas excludentes. Mesmo com o processo de democratização no Brasil, na década de 50, tal perspectiva continuou fundamentando a criação de escolas ditas especiais e a segregação daqueles que eram vistos como "anormais" (MEC, 2008). Em verdade, a escola exclui historicamente diversos grupos sociais (pobres, negros, mulheres, LGBTI etc.), sendo o grupo de PcD um dos que há muito tempo tem reivindicado e só recentemente tem encontrado apoio institucional, via políticas públicas, para mudar esse quadro.

Assim, a partir de uma perspectiva dos direitos humanos e do conceito de cidadania a todos e todas, a despeito das singularidades que constituem os sujeitos; práticas excludentes têm sido revistas - seja por meio da instauração de políticas públicas via legislação seja por meio de práticas instituintes no cotidiano escolar. Esse processo passa pela compreensão de quem sejam as $\operatorname{PcD}$ e de quais são as 
implicações, sobre esse grupo e sobre toda a sociedade, da instauração de escolas regulares inclusivas, "escolas da diferença", isto é, escolas cuja pedagogia

tem como mote questionar, colocar em dúvida, contrapor-se, discutir e reconstruir as práticas que, até então, têm mantido a exclusão por instituírem uma organização dos processos de ensino e de aprendizagem incontestáveis, impostos e firmados sobre a possibilidade de exclusão dos diferentes, à medida que estes são direcionados para ambientes educacionais à parte (ROPOLI, 2010, p. 04)

Diferentemente das históricas políticas excludentes, existentes desde a época imperial, por exemplo, tem-se entendido, então, que as escolas regulares com orientação inclusiva são os meios mais eficazes de combater atitudes discriminatórias (ROPOLI, 2010). Veja-se que essa é a orientação inferida a partir de convenções internacionais como as de Salamanca (1994) e Guatemala (1999), por exemplo. Assim, entende-se que estudantes com deficiência devem ter acesso a esse tipo de instituição, uma vez que "as escolas deveriam acomodar todas as crianças independentemente de suas condições físicas, intelectuais, sociais, emocionais, lingüísticas ou outras" (MEC, 2006, p.330).

A Convenção da Guatemala (1999), promulgada no Brasil pelo Decreto $\mathrm{n}^{\circ}$ 3.956/2001, compreende que as pessoas com deficiência possuem os mesmos direitos humanos e liberdades fundamentais que as demais pessoas. Assim, considera-se toda diferenciação ou exclusão que possa impedir ou anular o exercício dos direitos humanos e de suas liberdades fundamentais uma discriminação com base na deficiência. Tal posicionamento repercute nas instituições escolares na medida em que se reinterpreta a noção de educação especial, não mais significando apenas a criação de escolas "especiais", mas a eliminação de barreiras que impedem as PcD de acessar a escolarização regular (MEC, 2006).

Esse movimento implica contribuição para o desenvolvimento não apenas das PcD que ingressam na escola regular, mas também da própria escola, seu corpo docente, discente, gestão e demais trabalhadores. A inclusão, nesse sentido, contribui para a formação de todos os sujeitos do processo educacional e, por extensão, da sociedade. Nas palavras de Mantoan (2003, p 23, 30), 
A escola comum é o ambiente mais adequado para garantir o relacionamento entre os alunos com ou sem deficiência e de mesma idade cronológica, bem como a quebra de qualquer ação discriminatória e todo tipo de interação que possa beneficiar o desenvolvimento cognitivo, social, motor e afetivo dos alunos em geral. [...] Incluir é necessário, primordialmente para melhorar as condições da escola, de modo que nela se possam formar gerações mais preparadas para viver a vida na sua plenitude, livremente, sem preconceitos, sem barreiras.

Apesar do avanço que essas orientações legais representam; na prática, a efetivação da inclusão depende de reformulação de práticas educativas que transcendem a formalidade do texto legal, e a mobilização da comunidade escolar é central para essa efetivação. Nesse sentido, a pedagogia de projetos envolvendo todos/as os/as discentes, embora não seja a única ferramenta producente, se apresenta como aquela que propicia maior interação em atividades comunitárias, de trocas e (re)construção de conhecimentos entre alunos e alunas, independente de suas singularidades.

Além disso, a emergência da temática da inclusão é um aspecto positivo para a mobilização da comunidade escolar em volta de questões sociais e, por consequência, de um contexto que permite o agenciamento e, no caso pedagógico, como apontado acima, a apropriação e (re)construção de conhecimentos em prol da resolução dessas questões. É sobre o instrumento do projeto interdisciplinar, então, que trataremos na seção seguinte.

\section{A PROPOSTA DE PROJETOS E A INTERDISCIPLINARIDADE}

No processo de ensino e aprendizagem, o diálogo entre as bases tecnológicas exigidas pelo currículo escolar e a realidade, sobretudo as questões pertencentes à sociedade atual; é imprescindível. Nesse sentido, os temas transversais, advindos, muitas vezes, do próprio contexto dos estudantes, têm sido discutidos dentro de sala de aula a fim de tornar inteligíveis questões presentes nesse âmbito, de forma a proporcionar o exercício de cidadania e o pensamento crítico e reflexivo. A inclusão é uma dessas importantes questões sociais, sobretudo porque, no caso do contexto do IFSC-Gaspar, tem se apresentando como um 
aspecto constitutivo das práticas educativas locais.

O trabalho acerca dessa questão pode se dar por meio das diversas atividades escolares, tanto dentro de cada uma das disciplinas quanto por meio de projetos interdisciplinares, sendo que no âmbito desses últimos, a maior interação e construção colaborativa do conhecimento tem se mostrado significativa.

Esse aspecto se relaciona com o fato de que a compartimentalização do saber, típica da organização do conhecimento em disciplinas, já não tem conseguido dar respostas suficientes aos problemas globais da sociedade. Por tal motivo, na educação, tem-se procurado aproximar os campos de saber, de modo a tratar de tais problemas de forma colaborativa, por meio de projetos que transcendem os limites disciplinares e possibilitam respostas mais orgânicas às demandas sociais.

A proposta de uma aprendizagem baseada em projetos (ABP) permite, então, de forma dialogada, que docentes, discentes e, muitas vezes, a comunidade escolar e extraescolar, pensem e discutam sobre esses problemas de modo significativo, encontrando soluções eficazes. Assim, a ABP tornou-se instrumento importante na atual educação, visto que

[...] é um modelo de ensino que consiste em permitir que os alunos confrontem as questões e os problemas do mundo real que consideram significativos, determinando como abordá-los e, então, agindo de forma cooperativa em busca de soluções. (BENDER, 2014, p.09)

Ao pensar em problemas existentes na sociedade, o projeto aparece como uma forma de propor etapas de pesquisa, de ação e de solução de um problema a partir de um tema central. O tema central deve permear o planejamento na busca de caminhos e soluções do problema de forma a responder os objetivos iniciais e o sentido atribuído ao projeto. A ABP prevê, portanto, a construção colaborativa de conhecimentos por meio da investigação (BENDER, 2014).

Ao trabalhar em conjunto com as bases tecnológicas exigidas em cada disciplina escolar, tal instrumento propõe apresentar um plano de ações para o cumprimento de etapas com o intuito de atingir o objetivo principal, que é solucionar um problema. Desta forma, os estudantes, ao planejarem o roteiro e à medida que 
forem cumprindo as etapas previstas, percebem-se como protagonistas desse desenvolvimento.

A ABP prevê enquanto critérios:

1. Um currículo elaborado em torno de problema com ênfase em habilidade cognitivas e conhecimento; 2. Um ambiente de aprendizagem centrado no aluno, que utilize pequenos grupos, e uma aprendizagem ativa em que os professores atuem como facilitadores; 3 . Resultados dos alunos focados no desenvolvimento de habilidades, motivação e amor pela aprendizagem permanente. (BENDER, 2014, p. 25)

Apesar de o currículo escolar apresentar-se ainda de modo compartimentalizado, ou seja, com os saberes agrupados por conhecimentos específicos, os temas transversais possibilitam a criação de projetos interdisciplinares que, a partir da colaboração de cada disciplina, podem contribuir para a compreensão e solução de diversos tipos de problemas e daquele que é central ao próprio projeto. Assim, permite-se que as singularidades de cada disciplina possam ser trabalhadas, dialogadas e verificadas. O estudante, em sua relação cooperativa com o grupo, pode aprofundar seus conhecimentos sobre os conteúdos presentes nas unidades curriculares diante da resolução de problemas e reconhecer esses conteúdos tanto nas etapas do projeto quanto no alcance do objetivo final.

Além disso, a ABP sugere a autonomia dos estudantes sobre 0 desenvolvimento das etapas e a definição dos caminhos a serem tomados. Nesse contexto, o professor, enquanto orientador do tema e mediador desse desenvolvimento, coopera no cumprimento das etapas e na viabilidade de realização das atividades.

Ao propor esse tipo de aprendizagem, acredita-se que o envolvimento de duas ou mais disciplinas contribuem para reconhecimento da importância das disciplinas frente aos problemas encontrados na sociedade e o sentido de seus conteúdos para os estudantes, que percebem sua aplicação na resolução de problemas e a ampliação de conhecimentos.

Cabe ressaltar, no entanto, que a interdisciplinaridade não significa o 
rompimento da disciplinaridade, visto que a própria unidade disciplinar possui singularidades importantes e a compreensão de suas fronteiras é necessária para uma proposta interdisciplinar (GALLO, 2000). Em outras palavras, o que se enfatiza em projetos desse tipo é o "livre trânsito", o diálogo produtivo entre os diferentes campos do saber, "rompendo com suas fronteiras e buscando respostas para assuntos complexos." (GALLO, 2000, p. 05).

Hodiernamente, a acessibilidade tem se constituído uma preocupação social relevante. Uma questão com a qual as instituições precisam lidar no sentido de garantir acesso e permanência a toda cidadã e a todo cidadão, independente de suas singularidades. Assim, a escola, enquanto instituição educacional deve se debruçar sobre a questão, contribuindo para soluções eficazes. A questão aqui, então, conforme apontamos na seção anterior, é refletir sobre como a escola regular pode ser inclusiva, que tipos de conhecimentos e ações devem ser mobilizados, construídos para agir sobre essa questão social relevante. Um dentre os possíveis caminhos é o desenvolvimento de projetos interdisciplinares, a exemplo do que apresentamos a seguir.

\section{PLANEJANDO E EXECUTANDO O PROJETO INTERDISCIPLINAR}

Em termos práticos, todo o desenvolvimento do projeto se deu por meio das seguintes etapas: i) problematização de questões sociais relevantes ao contexto escolar e às turmas; ii) planejamento das etapas do projeto; iii) execução do projeto; iv) reflexão sobre as produções.

\section{ETAPA 01}

A primeira etapa se constituiu da emergência mesma da demanda pelo projeto, ou seja, da necessidade de refletir sobre que estratégias contribuiriam para possibilitar o acesso de todos os alunos e alunas, inclusive as pessoas cegas, a conhecimentos em Biologia (nesse caso, às observações da paisagem, da flora e da fauna que constituíram os estudos do naturalista inglês Charles Darwin); em Língua Portuguesa (nesse caso, à produção textual de gêneros com descrição de imagens e cenas) e em Artes (nesse caso, às produções de artes visuais). 
A construção do diorama e sua organização em exposição de arte surgiram, então, como forma de fazer mobilizar conhecimentos em prol da resolução tanto da questão de tornar significativos aos alunos e alunas os conteúdos trabalhados quanto torná-los acessíveis a todos os sujeitos envolvidos no processo educacional, incluindo aqui a própria PcD. Afinal, construir um diorama, que é um objeto expositivo tridimensional, demanda o agenciamento focal dos conteúdos disciplinares no sentido de ter que adequá-los às demandas contextuais: uso de escala menor, limitação do espaço de trabalho (salas de aula) e de exposição, manipulação proficiente de formas e texturas variadas e em alto-relevo, atendimento de prazo relativamente curto para a construção, entre outros aspectos.

Na prática, essa reflexão deu-se por meio da observação das dinâmicas nas aulas nas turmas dos primeiros anos por cada uma das docentes, contexto em que os alunos comumente apresentam maiores dificuldades de adaptação à nova modalidade de ensino (Ensino médio integrado ao técnico) e de apropriação dos conhecimentos da fase. Além disso, naquele período, uma das turmas contava com uma aluna cega matriculada e frequentando as aulas das três disciplinas em que o projeto se desenvolveu. Por fim, via-se ali também um contexto propício para a emergência de um trabalho colaborativo que visasse à inclusão da discente, uma vez que os próprios discentes, inclusive a aluna, mostravam-se dispostos a isso. Essas observações topicalizaram discussões entre as docentes e fizeram emergir a proposta do projeto, especialmente integrando as unidades de Artes e Biologia e, posteriormente, de Língua Portuguesa.

\section{ETAPA 02}

Tendo problematizado a questão posta acima, as docentes sugeriram a produção dos dioramas nos moldes de um projeto interdisciplinar e organizaram o trabalho de modo que cada uma das disciplinas focalizasse diferentes aspectos do projeto, sempre em articulação com a demanda posta: tornar os conteúdos curriculares significativos e acessíveis a todos e todas. Assim, em Biologia seriam trabalhados os conteúdos atinentes aos estudos de Darwin (evolução, tipos de solo, de plantas e de animais e suas relações com o clima, bem como a própria construção do conhecimento científico); em Artes, seriam trabalhados os aspectos 
de criação do objeto expositivo e de materiais de exposição de arte (elementos da linguagem visual, composição e proporção, matéria-prima, estética, planejamento, organização e montagem da exposição ) e em Português, as diferentes formas de linguagem e os aspectos dos gêneros discursivos (linguagem verbal e não verbal, descrição/audiodescrição, processos de adjetivação, focalização etc.).

Nessa etapa, também foi planejado um cronograma de atividades, elencando quantas, quais e quando seriam as aulas destinadas ao desenvolvimento do projeto, dentro da carga horária das disciplinas e também fora dela. Por fim, fez parte do planejamento uma ficha de avaliação das produções, a ser preenchida pelos próprios alunos e alunas, de modo a trabalhar a autocrítica; e também pelas docentes, uma vez que essas agem, conforme propõe uma visada vigotskiana, como facilitadoras mais experientes do processo.

Esse planejamento foi sendo realizado em conjunto com os discentes, havendo sempre a negociação do tempo para realizar as atividades, dos modos de organização dos grupos de trabalho, das funções dos membros de cada grupo, dos critérios de avaliação etc.

\section{ETAPA 03}

A realização propriamente do projeto interdisciplinar se deu por meio da execução do que fora planejado pelos grupos de trabalho em cada uma das turmas. Essa etapa ocorreu tanto durante a carga horária das disciplinas quanto em períodos extraclasse, sobretudo no que tange aos encontros entre os discentes e o Grupo de Trabalho de Materiais Adaptados. A realização completa do projeto durou aproximadamente 10 semanas (entre setembro e novembro de 2018), incluindo o planejamento.

A atividade foi realizada com as turmas da primeira fase dos cursos técnicos integrados em informática e em química. As turmas foram divididas em vinte e duas equipes, sendo onze equipes em cada um dos cursos. Por meio de sorteio, cada uma delas se responsabilizou pelo trabalho sobre uma localidade da viagem do Beagle. Apesar de Darwin (2014) ter visitado um número considerável de lugares durante a expedição, para este trabalho foram selecionados apenas vinte e dois 
lugares em função do espaço, do tempo e da infraestrutura disponíveis para o projeto.

Assim, os discentes leram o relato de Charles Darwin, pesquisaram sobre os componentes bióticos e abióticos e o contexto sócio-histórico da localidade sorteada. Com o apoio do professor de história, os estudantes tiveram uma aula específica sobre o século XIX na Europa, a fim de compreender como se organizava a sociedade europeia naquele momento, suas tecnologias, preconceitos, desejos etc. Posteriormente, esboçaram o diorama e listaram os materiais necessários para a criação. Os grupos elaboraram, então, um croqui, conforme a pesquisa e a descrição dos materiais necessários à elaboração do produto final. Para a listagem dos materiais, as equipes verificaram sua viabilidade e acessibilidade, visto que o público-alvo do projeto incluía pessoas com deficiência visual. Para isso, testaram as formas e a texturas e tiveram o auxílio dos professores e do público-alvo, especialmente da aluna Geovanice, que é cega e integrou uma das turmas realizadoras do trabalho.

Cada diorama media $40 \mathrm{~cm}$ x $30 \mathrm{~cm}$ e $20 \mathrm{~cm}$ (larg. x alt. x prof.) e teve que apresentar, por meio dos materiais, características da localidade que representava, de forma que o espectador pudesse tocar no objeto e perceber em relevo aspectos geológicos/biológicos que o constituíam (Figura 01). Os materiais utilizados foram: argila, arame, esponja, papel, tesoura, cola, serragem, pigmento, tinta, pincel, bonecos, entre outros.

Figura 01 - Quatro dioramas realizados pelos alunos.

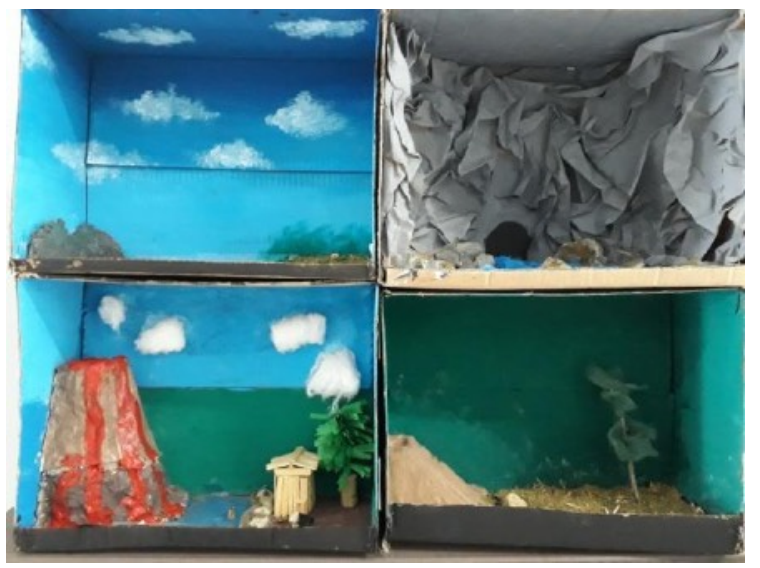

Fonte: Elaborado pelas autoras (2018). 
Durante as etapas de planejamento e construção dos dioramas, as equipes tiveram algumas dificuldades, como i) construir objetos que respeitassem, em termos de tamanho, à proporção em relação à situação real e ii) encontrar modelos de animais compatíveis com o relato. Desta forma, os grupos ajustaram os materiais disponíveis, adaptando-os às necessidades do diorama e também os substituíram por materiais semelhantes.

Durante o processo de finalização do objeto, as equipes iniciaram a elaboração de um roteiro para apresentação da construção, o que subsidiou a produção posterior da audiodescrição. Cada trabalho teve como título: Uma viagem com a Expedição Beagle, e como subtítulo: Nome da localidade visitada pelo Beagle. A apresentação teve como roteiro: i) introdução sobre a localidade estudada; ii) resumo do relato de Darwin; iii) descrição do diorama de forma detalhada e iv) finalização. A descrição detalhada do diorama foi uma das dificuldades das equipes, visto que as descrições precisavam de vários ajustes para contemplar todos do público-alvo, tais como: localização dos objetos no espaço do diorama, especificação dos materiais, formas, relação com o relato de Darwin, entre outras.

A partir do roteiro, as equipes elaboraram as audiodescrições, que foram disponibilizadas na plataforma do Youtube, no canal "Interdisciplinar IFSC Gaspar" (Figura 02) e apresentadas na exposição como QR- Code (Figura 03). 
Figura 2 - Canal “Interdisciplinar IFSC Gaspar”, no Youtube.

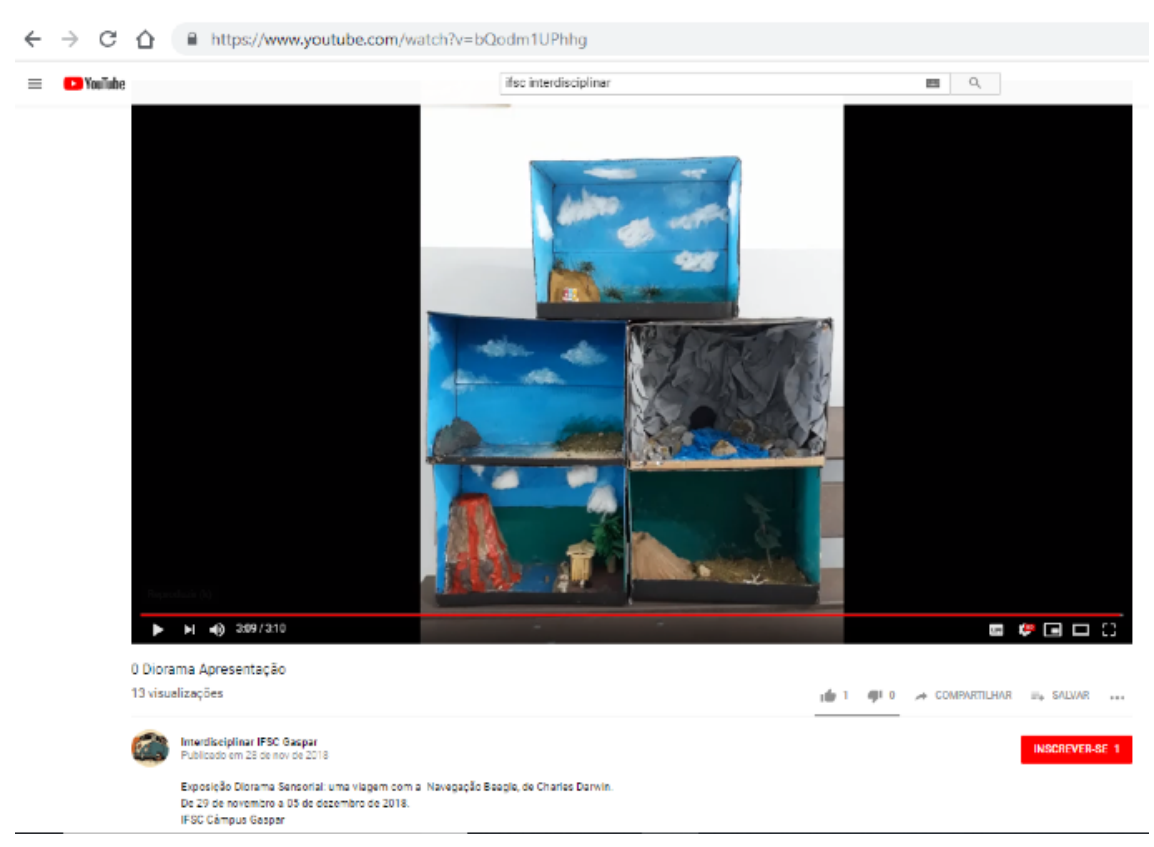

Fonte: Elaborado

pelas autoras (2018).

As audiodescrições foram captadas por gravadores de áudio no celular, editadas no programa Movie Maker para que se pudesse acrescentar a sonoplastia e, posteriormente, postadas na plataforma do Youtube, para criação do QR-Code. A criação do QR-Code demandou a utilização do programa online de criação de QRCode gratuito (https://br.qr-code-generator.com/). Após descarregar a imagem criada, o QR-Code foi impresso e aplicado na parte inferior da legenda em braille apresentada em cada um dos dioramas que compõem a exposição (Figura 03).

Figura 03 - QR-Code da Apresentação da Exposição.

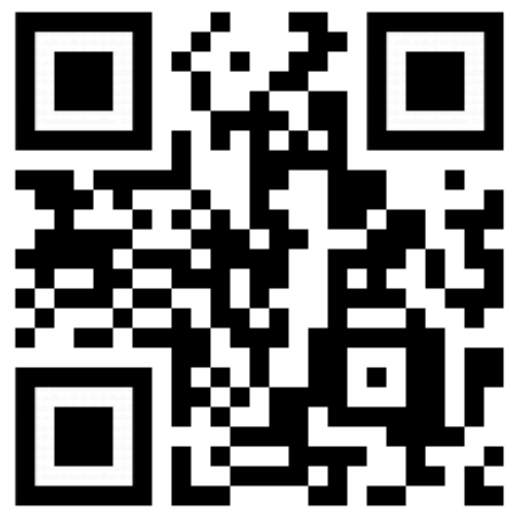

Fonte: Elaborado pelas autoras (2018). 
Além do roteiro e das audiodescrições, os grupos produziram uma legenda simples em braille (Figura 04). As legendas foram elaboradas em braille com indicação do título e subtítulo do diorama, nomes dos discentes produtores e indicação de sua turma. Para isso, com o apoio do Grupo de Trabalho de Materiais Adaptados (GTMA), cada equipe agendou um horário com as bolsistas do GTMA. Dessa forma, também se envolveram em uma atividade de pesquisa, ampliando o conhecimento sobre o alfabeto braille e o processo de sua elaboração, com o auxílio do GTMA.

Figura 04 - Exposição Diorama Sensorial - legenda QR e em Braille.

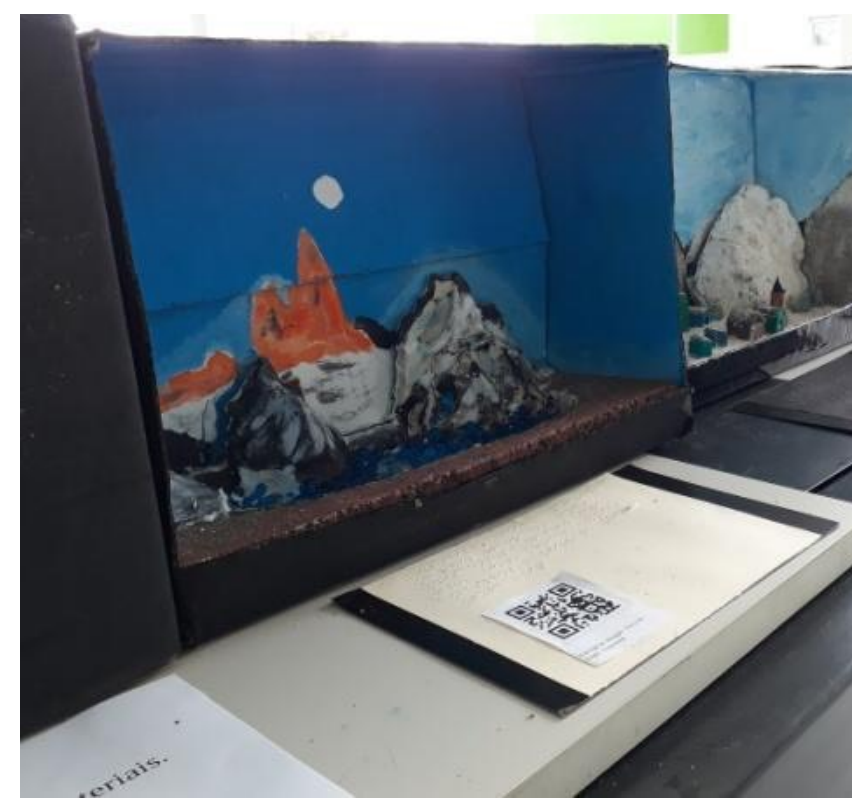

Fonte: Elaborado pelas autoras (2018).

Com o diorama, a legenda e a audiodescrição prontos, no dia 28 de novembro de 2018, as equipes montaram a exposição do diorama sensorial, conforme a ordem de navegação da expedição do Beagle. A exposição foi realizada no hall de entrada do IFSC Câmpus Gaspar, que permaneceu aberta à visitação até o dia 05 de dezembro de 2018. No último dia, a exposição recebeu a visita da ACBB - Sociedade Cultural Amigos do Centro Braille de Blumenau (Figura 05). Os participantes da ACBB interagiram com os dioramas, tocando e sentindo. Além disso, averiguaram as audiodescrições e as legendas em braille que acompanhavam 
os trabalhos. Dessa forma, puderam dar um parecer sobre a exposição.

Figura 05 - Exposição Diorama Sensorial - visita de integrantes da ACBB.

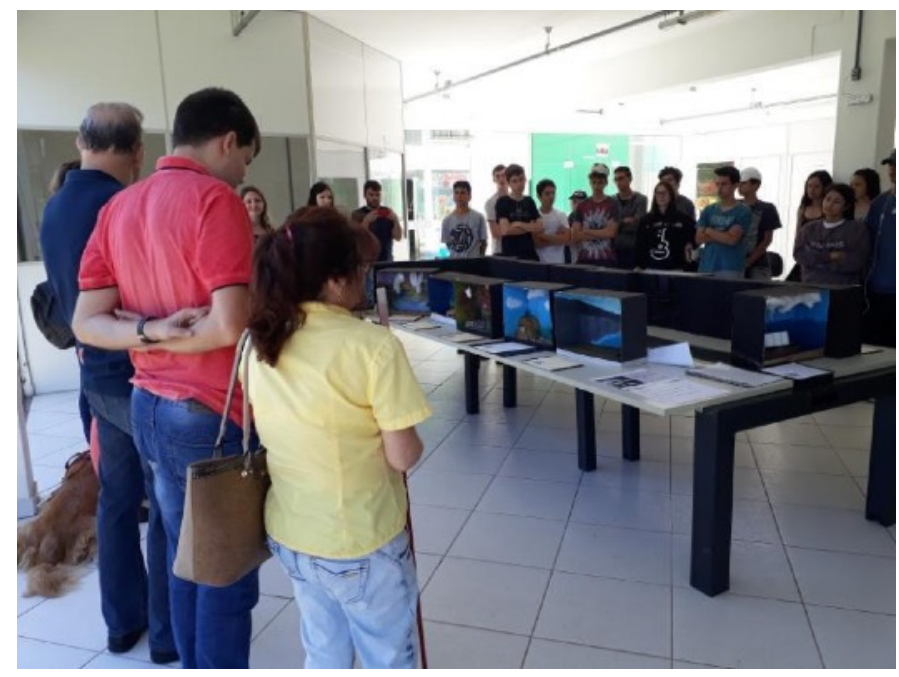

Fonte: Elaborado pelas autoras (2018).

O parecer da ACBB foi positivo, de forma a indicarem que a exposição fosse itinerante, propondo levá-la a outros espaços. Também apontaram como pontos positivos a disponibilidade do QR-Code para acessar as audiodescrições e as legendas em braille, ou seja, a preocupação com a acessibilidade e a inclusão. Alguns detalhes foram apontados com o intuito de melhorias: a atenção à ortografia em braille, que não foi revisada em alguns trabalhos. Além da ACBB, algumas turmas do campus puderam interagir com a exposição por meio de vendas nos olhos e, assim, experienciar parte da proposta do projeto, principalmente no se que se refere à prática da empatia, já que tentaram se relacionar com os objetos criados a partir da perspectiva das PcD.

\section{ETAPA 04}

As reflexões acerca dos trabalhos realizados foram feitas por meio de discussões durante as aulas posteriores ao término do projeto e também por meio das próprias avaliações que os alunos fizeram da atividade. Nesse caso, foram distribuídas listas de questões acerca do trabalho, com as seguintes perguntas:

1. Já conheciam a história da Navegação Beagle, de Charles Darwin, antes deste 
trabalho?

2. A partir deste trabalho, o que se entende por diorama?

3. Na opinião do grupo, por quê foi importante estudar e realizar o diorama?

4. Quais são os aspectos artísticos identificados no diorama?

5. Quais foram as dificuldades encontradas durante a realização do diorama?

6. Quais foram os ajustes realizados?

7. Quais foram os pontos positivos com o trabalho do diorama?

8. Como foi propor um trabalho para um público específico? Justifique sua resposta.

9. Como foi trabalhar em equipe? Relate sobre o que cada um fez pelo trabalho.

10. O que o grupo pensa a respeito das avaliações interdisciplinares?

11. Que nota o grupo atribui ao diorama realizado? Justifique a nota.

\section{IMPLICAÇÕES DO PROJETO PARA AS PRÁTICAS DE ENSINO- APRENDIZAGEM E PARA A INCLUSÃO}

\section{1 (RE)CRIANDO CONHECIMENTOS EM ARTE}

A presença da arte no planejamento, no processo criativo e no resultado final do projeto interdisciplinar deu-se a partir da reflexão sobre a acessibilidade dos objetos artísticos em espaços expositivos. Essa reflexão permitiu pensar no objeto criativo como mediador dos conhecimentos das áreas envolvidas e a importância da presença da arte no desenvolvimento do projeto, na elaboração do objeto tátil, visual e sonoro.

Os conhecimentos artísticos foram trabalhos desde o planejamento, o desenvolvimento do diorama e a sua apresentação. Durante o planejamento, foram apresentados exemplos de inclusão em museus, como audiodescrições e objetos em alto-relevo e tridimensionais. Dessa forma, a atividade de elaboração do croqui possibilitou pensar e repensar o diorama e os possíveis materiais a serem utilizados, possibilitando a experiência de (re)construir conhecimentos no processo de criação.

Para a elaboração do croqui, foram realizadas pesquisas de imagens dos lugares, em livros e internet, a fim de se obter de referências da paisagem. Além disso, a própria descrição do relato de Darwin possibilitou construir visualmente o 
diorama. Alguns elementos da linguagem visual, como forma e textura, foram trabalhados durante o processo de criação com o foco no público com deficiência visual. O diorama, enquanto uma representação tridimensional de uma situação, foi desenvolvida conforme o relato de Darwin.

Durante o processo de desenvolvimento do diorama, por diversos momentos, as equipes averiguaram a distribuição dos materiais, suas formas e texturas para contemplá-lo enquanto objeto tátil. Durante o processo, alguns materiais foram substituídos, acrescentados ou adaptados para contemplar com maior aproximação o relato de viagem. Com o diorama realizado, a leitura dramática foi trabalhada com foco na audiodescrição, para o que utilizou-se a tecnologia, como gravação, edição e publicação. As audiodescrições foram importantes no complemento da compreensão dos objetos expostos e trouxeram informações e curiosidades dos lugares trabalhados, contextualizando o objeto artístico. A clareza no detalhamento e inclusão de sons pertencentes à paisagem (pássaros, ondas), enriqueceram esteticamente a audiodescrição.

Por fim, foi trabalhado sobre o espaço expositivo, a importância da curadoria e da montagem de exposição; as possibilidades de montagem; o cuidado com a distribuição dos objetos. Tudo isso permitiu montar em conjunto e em conformidade a ordem da viagem e a colocação dos materiais necessários, como a legenda em braille com QR-Code. Desta forma, observou-se que os conhecimentos artísticos trabalhados no projeto foram relevantes para a compreensão do processo criativo, da exposição e da inclusão em espaços expositivos.

\subsection{DANDO NOVOS SENTIDOS À BIOLOGIA}

O ensino de Biologia em sala de aula muitas vezes privilegia apenas o uso da visão: explicações de esquemas desenhados no quadro ou projetados, observações de figuras em livros didáticos, demonstrações de experimentos, estudo de lâminas ao microscópio etc. Tal fato, embora seja bastante adequado à natureza do próprio objeto de conhecimento, pode ser limitador quando essa adequação não se estende ao público que participa do processo de (re)construção deste saber. Esse é o caso, por exemplo, de alunos com cegueira. Nesse contexto, uma prática educativa comprometida deve questionar-se sobre como propor atividades que permitam 0 
engajamento desses estudantes, cujos principais sentidos empregados no ambiente escolar são a audição e o tato. Além disso, é importante refletir ainda sobre como possibilitar a alunos e alunas videntes a experiência da Biologia através dos (e de) outros sentidos, uma vez que isso pode também tornar o processo de aprendizagem mais significativo a todos e todas.

Em relação aos estudantes com cegueira em sala, mas também aos visitantes recebidos na exposição, o projeto do diorama se constitui numa ferramenta tanto para divulgação dos conhecimentos científicos quanto para reflexão sobre o modo como esses conhecimentos são construídos. Veja-se que as respostas do questionário apontam que 15 das 22 equipes não conheciam ou nunca tinham ouvido falar da viagem do Beagle até o momento do projeto. Embora entre essas equipes, alguns discentes já tivessem ouvido o nome de Charles Darwin, isso ocorreu apenas de modo superficial, como um nome conhecido mundialmente por algum motivo desconhecido dos alunos e alunas.

Constantemente, a Biologia é criticada como uma disciplina que traz uma série de nomes a serem memorizados (KRASILCHIK, 2016). Algo similar parece ocorrer quando os professores tentam acrescentar ao tratamento de conteúdos elementos da história da Biologia. O nome é memorizado, mas não há nenhum conhecimento sobre o que de fato fizera aquela personalidade; sobre qual teria sido sua contribuição para a ciência; sobre como chegou às ideias que se tornaram conhecidas e revolucionam campos de conhecimento.

No projeto do diorama, a escolha pelo naturalista inglês se deu justamente por este ser lembrado pela teoria da evolução, apesar de sua contribuição original ter sido, na verdade, a seleção natural. Pouco ainda é discutido com os alunos em sala de aula sobre como essa viagem, que durou quase cinco anos, influenciou na escrita do livro A Origem das Espécies (MELLO, 2008). Tal fato aponta para a necessidade de provocar a reflexão entre os alunos e alunas a respeito do modo de construção dos conhecimentos científicos, que não são elaborados de forma instantânea como muitas manchetes sobre "descobertas" nos fazem crer (RIBEIRO; BOOS, 2014). Ao contrário, esse conhecimento se constrói ao longo do tempo, por meio de observação cuidadosa, de muitas leituras, de coletas de dados etc.; e pode 
ser influenciado, ainda, pelos ideais vigentes em cada época e em cada sociedade.

Além de tudo isso, o fato de a proposta se tratar de um diorama tátil faz com que a natureza da divulgação do conhecimento seja mais ampla. Veja-se que em museus de ciências naturais, os dioramas geralmente representam um bioma com sua fauna e flora em tamanho próximo ao natural. Os dioramas museais permitem a observação da "cena" através de uma vitrine, poucas vezes contando com outros estímulos como sons, cheiros e diferenças de temperatura do ambiente de exposição1.

Assim, pessoas cegas acabam excluídas de usufruir de exposições geralmente por falta de acessibilidade (legendas em braille, audiodescrição, recursos táteis), o que as deixa à margem do conhecimento produzido pela ciência (e também por outros campos, já que essa prerrogativa se estende a muitas exposições artísticas, por exemplo). A possibilidade de tocar um objeto elaborado a partir da pesquisa de um texto clássico da história da Biologia, escrito por uma figura relevante para a ciência mundial como Charles Darwin, e ouvir a narração dessa expedição, com recursos sonoros que levam em consideração a descrição do espaço e do contexto histórico; é uma oportunidade de letramento científico principalmente às pessoas cegas, além de um convite a embarcar numa viagem utilizando os seus sentidos e a sua imaginação.

Para os alunos sem restrições visuais, em resumo, o diorama configura-se como uma atividade que ressignifica conteúdos de Biologia, geralmente observados em duas dimensões (a partir de fotos e textos), transpondo-os para a tridimensionalidade, utilizando o tato e a audição. Além disso, o projeto faz com que os estudantes precisem trabalhar em grupo, dividir responsabilidades, pensar nas formas mais apropriadas de fazer o sentido acerca do texto redigido por Darwin ser apreendido pelas pessoas com cegueira. Algumas equipes precisam ainda lidar com sentimentos como antipatia/simpatia pela localidade descrita e pelo modo como

\footnotetext{
1 Veja-se que uma das autoras, por exemplo, visitou o Museu Americano de História Natural em 2011 e observou que os dioramas não possuíam legendas em braille, nem recursos táteis ou audiodescrição. Entretanto, na página oficial da instituição (www.amnh.org), é indicada a possibilidade de agendamento de visitas especiais para o público cego, em que seriam fornecidas explicações orais mais detalhadas pelos guias e a chance de tocar alguns objetos. Esse tipo de visita precisa ser programada com pelo menos duas semanas de antecedência, restringindo o acesso espontâneo do público cego.
} 
foram descritas. Veja-se que alguns grupos, inclusive, não concordaram com os comentários tecidos pelo próprio jovem (e vitoriano) Darwin.

Por fim, em pelo menos metade das equipes, como constatado na autoavalição, houve a percepção de que o projeto do diorama foi importante, nas palavras dos alunos, para "se colocar no lugar dos cegos". Sabemos que uma empatia total é muito difícil de ser alcançada, mas provocar esse deslocamento do seu lugar de privilégio, de pessoa vidente em uma sociedade normovisual e gerar reconhecimento dessa condição diferente (e válida) dos cegos de estar no mundo, torna esse projeto mais significativo para alunos e professores.

\subsection{VERTICALIZANDO A REFLEXÃO SOBRE OS USOS DA LÍNGUA PORTUGUESA}

Aspectos do trabalho sobre Língua Portuguesa estiveram presentes na produção dos dioramas. De maneira geral, isso ocorreu na abordagem dos diferentes tipos de linguagem (visual/artística, verbal/referencial) e, principalmente, no trabalho de produção escrita (roteiro) como base para produção de texto oral (audiodescrição). Nesse contexto, foram trabalhadas tanto as dimensões contextuais quanto textuais que integram esses gêneros discursivos produzidos.

No que tange à dimensão contextual, a participação de interlocutores externos à comunidade do campus, e especialmente o fato de esse público incluir pessoas com deficiência visual, fez com que os discentes se engajassem na atividade, de modo que ampliaram seu repertório social, discursivo e cultural. Isso se deu não apenas porque produziram gêneros pouco familiares, mas também porque a situação sociodiscursiva pressupunha o domínio de estratégias linguísticas que atendessem de modo proficiente a interlocutores específicos, algo também novo para a maioria dos alunos e alunas envolvido/as na atividade.

Considerando isso, as ações sobre a linguagem, nesse caso, se fizeram presentes por meio de atividades epilinguísticas (GERALDI, 1990), principalmente. Assim, os alunos demonstraram maior preocupação - o que repercutiu na produção final - com os interlocutores reais de suas produções, afinal tinham o que dizer, para que dizer, a quem dizer e trabalharam sobre as estratégias de fazê-lo. Nesse último 
caso, desenvolveram competências relacionadas à adequação da tipologia textual (descrição) à situação de uso (exposição de arte que inclui o público com deficiência visual). Também houve maior cuidado com o uso das adjetivações e as diferenças entre formas mais ou menos objetivas de descrição, cuidando assim dos aspectos estilísticos dos enunciados construídos.

Por fim, especificamente no que tange ao gênero oral, houve o trabalho de reflexão linguística sobre questões prosódicas, por exemplo. As atividades de reescrita e regravação foram os momentos mais significativos para que houvesse a reflexão epilinguística e o fato de a atividade envolver grupos de trabalho fez com que houvesse trocas mais significativas de conhecimento, uma vez que, conforme propõe Geraldi (1990), havia, de fato, leitores reais às produções, o que foi possibilitado pela escolha de trabalhar via projeto interdisciplinar, que pode ser entendido aqui como sendo o que Kleiman (2007) chama de projeto de letramento.

\section{CONCLUSÕES}

O projeto dos dioramas sensoriais, além de ser uma ferramenta, cujo produto contribui para mediação entre o público e a obra de arte, os objetos táteis, sonoros e visuais, possibilita a aproximação de públicos diversos e a compreensão da importância da prática interdisciplinar nos processos educativos.

A elaboração dos dioramas sensoriais, para além do objeto visual, foi realizada para ser sentida pelo público, por meio de sensações e percepções, e permitiu trazer para o campo tridimensional o relato e o registro teórico da expedição Beagle e elementos artísticos em sua apresentação.

O projeto procurou valorizar as unidades curriculares envolvidas por meio da pesquisa e de práticas interdisciplinares e a aproximação do público aos conhecimentos de cada unidade curricular e à viagem de Charles Darwin e linguagens artísticas. O projeto buscou, ainda, mostrar aos alunos envolvidos a importância de pesquisar, analisar e elaborar o trabalho de forma que contemplasse a proposta e o público com sucesso, além da relevância da aprendizagem baseada em projeto interdisciplinar na obtenção do conhecimento de cada área. Apesar de o diorama estar relacionado às exposições de história natural e ciências, esperamos 
que este projeto interdisciplinar possibilite um desdobramento de futuros projetos que venham a trabalhar com a inclusão e demais áreas do conhecimento.

\section{AGRADECIMENTOS}

Agradecemos ao Instituto Federal de Santa Catarina Câmpus Gaspar pelo apoio às práticas interdisciplinares e ao Grupo de Trabalho de Materiais Adaptados do IFSC Câmpus Gaspar, nas pessoas de Everton Anselmini, Maria Fernanda Ziermmermann e Ana Julia Volpi. Agradecemos também o apoio do professor de História, Mateus Melo, da aluna Geovanice Policeno e da Associação Cultural Amigos do Braille de Blumenau pela visita e apreciação dos trabalhos.

\section{REFERÊNCIAS}

BENDER, William N. Aprendizagem baseada em projetos: educação diferenciada para o século XXI. Tradução Fernando de Siqueira Rodrigues. Porto Alegre: Penso, 2014.

BRASIL. Decreto $N^{\circ} 3.956$, de 8 de outubro de 2001. Promulga a Convenção Interamericana para a Eliminação de Todas as Formas de Discriminação contra as Pessoas Portadoras de Deficiência. Guatemala: 2001.

Lei No 13.146, de 6 de julho de 2015. Institui a Lei Brasileira de Inclusão da Pessoa com Deficiência (Estatuto da Pessoa com Deficiência).

DARWIN, Charles. Viagem de um naturalista ao redor do mundo. Tradutor Pedro Gonzaga. Porto Alegre: L\&PM Pocket, 2014.

GALLO, Silvio. Transversalidade e educação: pensando uma educação não-disciplinar. IN: ALVES, Nilda; GARCIA, Regina Leite (orgs.). O Sentido da Escola. Rio de Janeiro: DP\&A, 2000. Disponível em: <http://www.lite.fe.unicamp.br/papet/2003/ep403/ transversalidade_e_educacao.htm_. Acesso em 17 mar. 2019.

GERALDI, João Wanderley. Portos de passagem. 4. ed. São Paulo: Martins Fontes, 1997.

IFSC. Plano de Desenvolvimento Institucional 2015-2019. Florianópolis, 2015. Disponível em: <https://pdi.ifsc.edu.br/files/2015/07/PDI_IFSC_revisado_2017.pdf> Acesso em 26 jun 2019.

KLEIMAN, Angela. Letramento e suas implicações para o ensino de língua materna. Signo, Santa Cruz do Sul, RS, v. 32, n. 53, p. 1-25, 2007.

KRASILCHIK, Myriam. Prática de Ensino de Biologia. 4. ed. São Paulo: EDUSP, 2016.

MANTOAN, Maria Teresa Eglér. Inclusão escolar: O que é? Por quê? Como fazer? 2. ed. São Paulo: Moderna, 2003

MELLO, Aline de Castilhos. Evolução biológica: concepções de alunos e reflexões didáticas. Porto Alegre, RS, 2008. 114f. Dissertação (Mestrado em Educação em Ciências e Matemática) - Pontifícia Universidade Católica do Rio Grande do Sul, PUCRS, 2008.

MINISTÉRIO DA EDUCAÇÃO (Brasil). Secretaria de Educação Especial. Direito à educação: subsídios para a gestão dos sistemas educacionais - orientações gerais e 
marcos legais. Brasília, 2006, 343p.

Secretaria de Educação Continuada, Alfabetização, Diversidade e Inclusão. Política Nacional de Educação Especial na Perspectiva da Educação Inclusiva. Brasília, 2008, 19p. Disponível em: <http://portal.mec.gov.br/arquivos/pdf/ politicaeducespecial.pdf>. Acesso em 01 abr 2019.

SANTOS, Tiago Ribeiro; BOOS, Alessandra. As condições do dizível: um exame sociológico das estratégias do campo jornalístico sobre a paleontologia. In: SOUZA, Carlos Alberto de; MORALES, Ofélia Elisa Torres (orgs). Coleção Mídias Contemporâneas: possibilidades e desafios vol.I. Ponta Grossa: UEPG, 2014, p.46-60.

ROPOLI, Edilene Aparecida. A educação especial na perspectiva da inclusão escolar: a escola comum inclusiva. Brasília: Ministério da Educação, Secretaria de Educação Especial; Fortaleza: Universidade Federal do Ceará, 2010. 